\title{
RETRACTION \\ AUTONOMOUS GROUP TESTING BASED FAULT TOLERANCE IN RECONFIGURABLE LOGIC DEVICES
}

\author{
[J. Circuits, Syst. Comput., Vol. 19, No. 6 (2010) 1199] \\ DOI: $10.1142 / \mathrm{S} 0218126610006827$ \\ JAVAD SABABEH \\ College of Electrical Engineering, \\ Iran University of Science and Technology, \\ Narmak, Tehran, Iran \\ KARIM MOHAMMADI \\ College of Electrical Engineering, \\ Iran University of Science and Technology, \\ Narmak, Tehran, Iran
}

Published 11 July 2013

\begin{abstract}
It has been found by the office of the Compliance \& University RIO at the University of Central Florida (UCF) on behalf of Robert DeMara and Carthik Sharma that the concerned paper contains original text, tables, and figures from the sources authored or co-authored by the complainant. The respondent (Javad Sababeh) rebutted with two emails and stated that he had used the complainant's ideas and some text in the source papers. After carefully examining the materials provided by both sides, and considering the weight of evidence available and the request of the office of the Compliance \& University RIO at the UCF, we retract this article.
\end{abstract}

